\title{
The risk factors for children with primary nephrotic syndrome: a systematic review and meta-analysis
}

\author{
Zhifang Zheng ${ }^{1}$, Guoli Chen ${ }^{2}$, Xiaoqing Jing ${ }^{1}$, Lirui Liu $^{1}$, Lixin Yang ${ }^{1}$ \\ ${ }^{1}$ Department of Pediatric Medicine, Affiliated Hospital of Chengde Medical College, Chengde, China; ${ }^{2}$ Department of General Surgery 1, Affiliated \\ Hospital of Chengde Medical College, Chengde, China \\ Contributions: (I) Conception and design: Z Zheng; (II) Administrative support: Z Zheng; (III) Provision of study materials or patients: G Chen; (IV) \\ Collection and assembly of data: L Liu; (V) Data analysis and interpretation: L Yang; (VI) Manuscript writing: All authors; (VII) Final approval of \\ manuscript: All authors. \\ Correspondence to: Zhifang Zheng. Department of Pediatric Medicine, South Branch, Affiliated Hospital of Chengde Medical College, Zhuanwayao \\ Block, High-Tech Industrial Development Zone, Chengde 067000, China. Email: zzf1615@126.com.
}

Background: To evaluate the risk factors of primary nephrotic syndrome (PNS) with urinary tract infection (UTI) in children.

Methods: Multiple databases including PubMed, Excerpta Medica Database (EMBASE), Web of Science (WOS), the Cochrane Library, and China National Knowledge Infrastructure (CNKI) were used to search for relevant studies, which were full-text articles involved in the evaluation of differences between PNS with UTI and without UTI. All included articles were assessed for quality and the data analyses were conducted with Review Manager (5.4). Forest plots, sensitivity analysis, and bias analysis were also performed on the included articles.

Results: Eight studies were included in this meta-analysis, with a total of 3,274 patients. Meta-analysis showed that a low level of serum albumin [mean difference (MD): $-0.32 \mathrm{~g} / \mathrm{dL} ; 95 \%$ confidence interval (CI): (-0.55, -0.08); P=0.008], a low level of serum total protein [MD: $-0.16 \mathrm{~g} / \mathrm{dL} ; 95 \% \mathrm{CI}:(-0.20,-0.12)$; $\mathrm{P}<0.00001]$, a high level of urinary protein [MD: $5.09 \mathrm{mg} / \mathrm{d} ; 95 \% \mathrm{CI}:(3.13,7.05) ; \mathrm{P}<0.00001]$, a lower level of serum urea nitrogen [MD: $-0.10 \mathrm{mg} / \mathrm{dL} ; 95 \% \mathrm{CI}:(-0.18,-0.02) ; \mathrm{P}=0.01]$, and a higher level of serum cholesterol [MD: $2.26 \mathrm{mg} / \mathrm{dL}$; 95\% CI: $(0.74,3.78)]$ had a higher risk of PNS with UTI. There was no obvious publication bias among included studies.

Discussion: Our research demonstrated that a low level of serum albumin, a low level of serum total protein, a high level of urinary protein, a low level of serum urea nitrogen, and a high level of serum cholesterol were the risk factors of PNS with UTI in children.

Keywords: Primary nephrotic syndrome (PNS); urinary tract infection (UTI); risk factor; children

Submitted Sep 07, 2021. Accepted for publication Nov 11, 2021.

doi: $10.21037 /$ tp-21-468

View this article at: https://dx.doi.org/10.21037/tp-21-468

\section{Introduction}

Primary nephrotic syndrome (PNS) is the most common glomerular disease and chronic kidney disease in childhood (1-3). Due to the increased permeability of the glomerular filtration membrane, a large amount of protein is lost from urine, resulting in significant proteinuria, hypoproteinemia, edema, and hyperlipidemia $(4,5)$. PNS refers to those caused by glomerular disease, the exact cause and pathogenesis are not yet fully understood. It is unanimously recognized that it is an immune-mediated inflammatory disease. Compared

\footnotetext{
$\wedge$ ORCID: 0000-0001-6412-2515.
} 
with adults, children are more prone to PNS, with 2-7 cases per 100,000 children every year (6). In children, it is mainly minimal degenerative nephropathy, mesangial proliferative nephritis and focal segmental glomerulosclerosis, but in adult, it is mainly mesangial proliferative nephritis and membranous proliferative nephritis (3).

Urinary tract infection (UTI) is the second most common complication of PNS (7). Among all the infections, UTI is of special concern as most of the UTIs in PNS are asymptomatic, which easily leads to missed diagnosis and misdiagnosis of asymptomatic bacteriuria, and affects the efficacy of PNS treatment $(8,9)$. The risk of UTI before the age of 14 is about $1-3 \%$ in boys and $3-10 \%$ in girls (10). The incidence rate of UTI varies from $4 \%$ to $0.4 \%$ in school age and preschool children. In children with PNS, the incidence of UTI is about $30 \%$ (11).

Studies have shown that UTI has a higher incidence in children with recurrent PNS (12-14). UTI may be the cause of decreased hormone sensitivity and the recurrence of renal disease (15). In severe cases, UTI may lead to persistent renal damage, scarring, and even end-stage renal disease (16). The possibility of UTI should be considered in PNS patients who have been hospitalized repeatedly or for a long time. Therefore, early and accurate diagnosis and treatment of UTI is important in these patients $(17,18)$.

Although it is important to explore the risk factors of PNS with UTI in children for treatment and prevention, there is no systematic evaluation to estimate the risk factors worldwide. Therefore, we conducted a search for relevant studies about the risk factors for PNS with UTI, and performed the first systematic review and meta-analysis to study the risk factors of PNS with UTI in children.

We present the following article in accordance with the PRISMA reporting checklist (available at https://dx.doi. org/10.21037/tp-21-468).

\section{Methods}

\section{Literature search strategy}

Seven electronic databases, including PubMed, Excerpta Medica Database (EMBASE), Web of Science (WOS), the Cochrane Library, and China National Knowledge Infrastructure (CNKI), were systematically searched from their inception until July 2021. We used the following keywords: (I) primary nephrotic syndrome; (II) urinary tract infection; (III) children. After that, the terms were combined using the Boolean operator "AND" in order to obtain articles that included two or more of the words used in the search. We performed a comprehensive search to identify all relevant studies regardless of language or publication status (published, unpublished, in press, and ongoing). Additional reports were identified by reviewing the reference lists of eligible studies and review articles.

\section{Study selection}

The studies had to fulfill the following criteria to be included in the analysis:

(I) Patients younger than 18 years old;

(II) Patients with PNS;

(III) Containing indicators evaluating the difference between PNS with UTI and without UTI;

(IV) Only articles with the full text available were selected.

Studies were excluded for the following reasons:

(I) Research did not meet the inclusion criteria;

(II) The risk factors of interest were not reported or impossible to use;

(III) Review, abstract, or duplicate publication.

\section{Data extraction and quality assessment}

Data were extracted in duplicate by two investigators independently and were input into a dedicated database. The following details were extracted whenever available: first author's name, patient age and gender, country of origin, year of publication, language, sample size, years of onset, and risk factors of interest. The quality of studies included in the review was evaluated by two independent reviewers through subjective judgment, with differences resolved by consensus or through a third reviewer if required. The Cochrane risk of bias tool 16 was used to reveal the risk of bias, and Review Manager was used to generate the risk of bias graph.

\section{Statistical analysis}

Review Manager (version 5.4, The Cochrane Collaboration, 2020) was adopted to estimate the difference of risk factors among selected reports. Continuous variables were evaluated by the mean difference (MD). Dichotomous variables were evaluated by the relative risk (RR). The chisquare test was used to test the heterogeneity among the included studies, and the heterogeneity was quantified by combining with $\mathrm{I}^{2}$. $\mathrm{I}^{2}$ values of $25 \%, 50 \%$, and $75 \%$ 


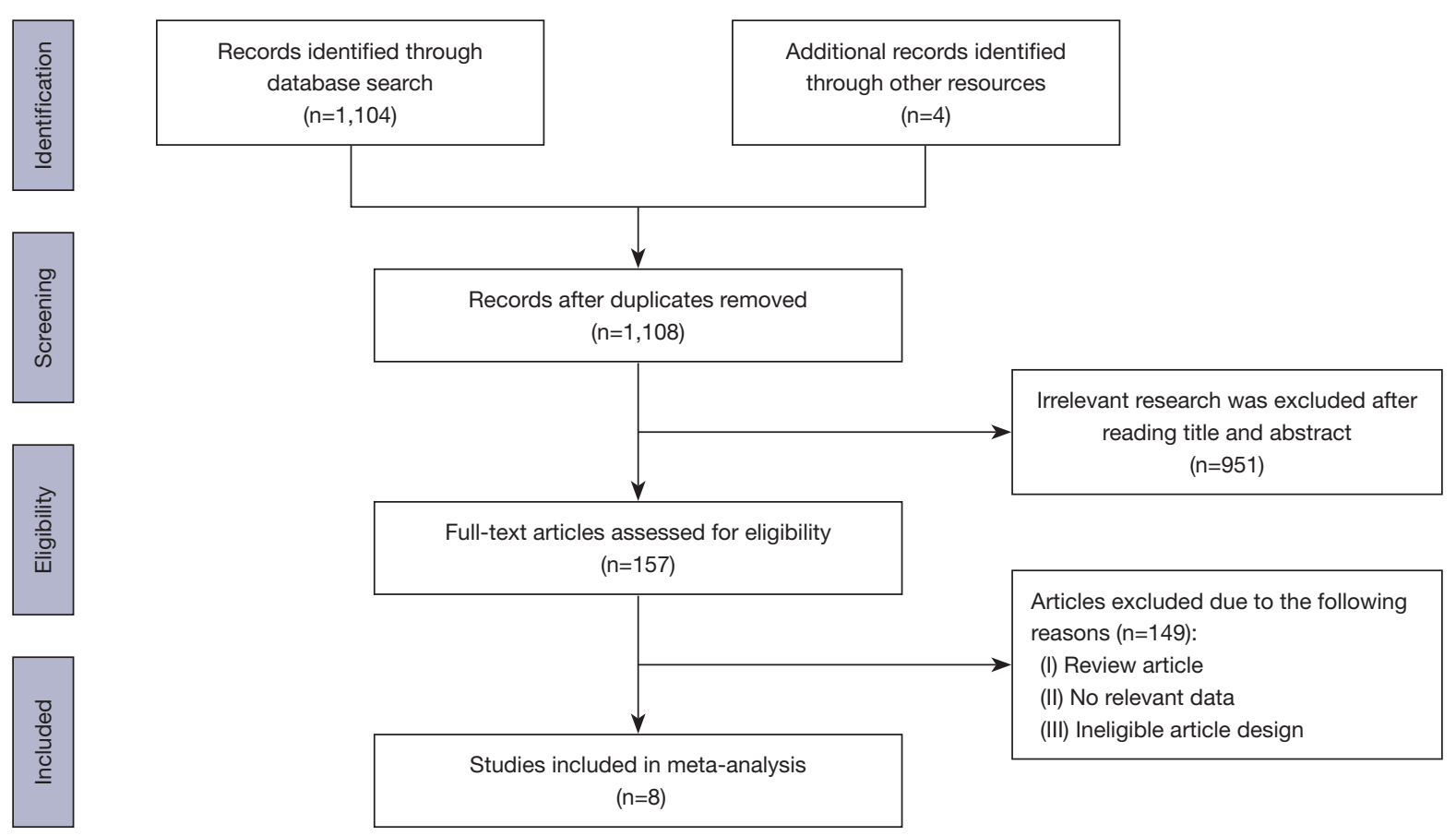

Figure 1 Flowchart of study selection.

were regarded as low, moderate, and high heterogeneity, respectively. A random effects model was used if heterogeneity was observed, while a fixed effects model was applied in the absence of inter-study heterogeneity. We also planned to perform sensitivity analyses based on the quality and weight of the trials by excluding each individual trial in turn. Publication bias assessments using a funnel plot and Egger's test were conducted to assess publication bias.

\section{Results}

\section{Search process}

A total of 1,177 articles were identified by the screening electronic search strategy. After removal of duplicates and screening through the titles and abstracts, 1,020 articles were excluded. Of the remaining 157 full-text articles, 149 were also removed as they were ineligible article designs or had no relevant data. Finally, 8 studies met our inclusion criteria and were selected for the present meta-analysis (19-26). Figure 1 shows the details of our literature search and selection process.

\section{Characteristics of included studies}

The basic features of the included studies are shown in
Table 1. Of the 8 studies, 6 studies were published in English, 2 were in Chinese, 3 studies were from Bangladesh, 2 were from China, 2 were from India, and the other 1 was from Iran. These studies contained a total of 3,274 PNS patients (696 with UTI and 2,578 without UTI). The prevalence of UTI ranged from $15.0 \%$ to $50.8 \%$. The risk factors of interest included serum albumin, serum total protein, urinary protein, serum urea nitrogen, serum cholesterol, serum triglycerides, and serum creatinine.

\section{Results of quality assessment}

Direct comparisons and the risk of bias assessment were performed using Review Manager (version 5.4). Among the included studies, a high risk of attrition bias was found in 3 studies, 2 studies showed a high risk of reporting bias, and 1 showed a high risk of performance bias (Figure 2). Figure 3 presents a summary of the risk of bias for each included study.

\section{Results of heterogeneity tests}

Serum albumin and serum total protein

In 8 studies involving 3,274 patients, a lower level of serum albumin had a higher risk of PNS with UTI [MD: 
Table 1 Basic characteristics of the included studies in the systematic review

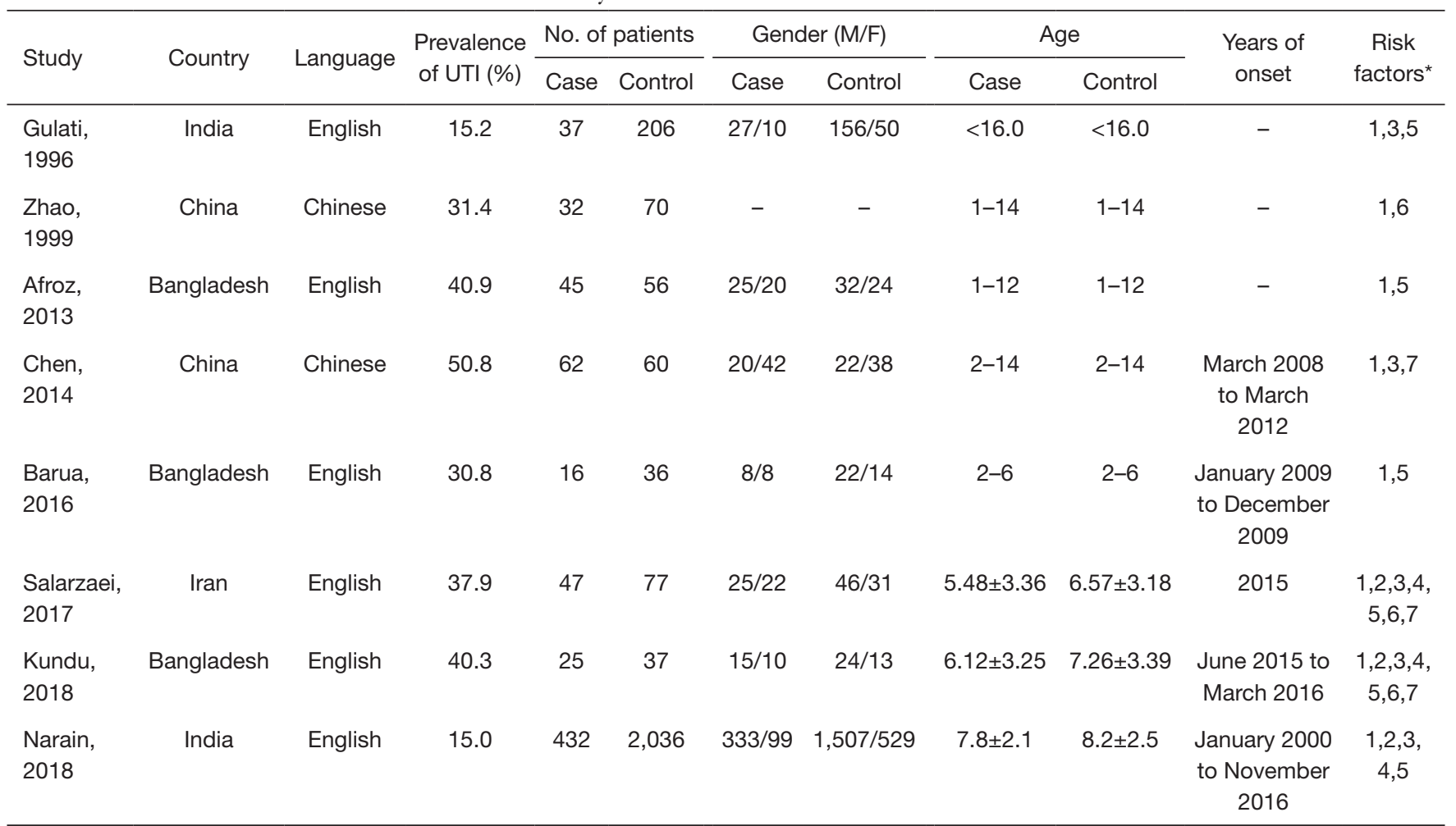

*, 1: serum albumin; 2: serum total protein; 3: urinary protein; 4: serum urea nitrogen; 5: serum cholesterol; 6: serum triglycerides; 7: serum creatinine. UTI, urinary tract infection.

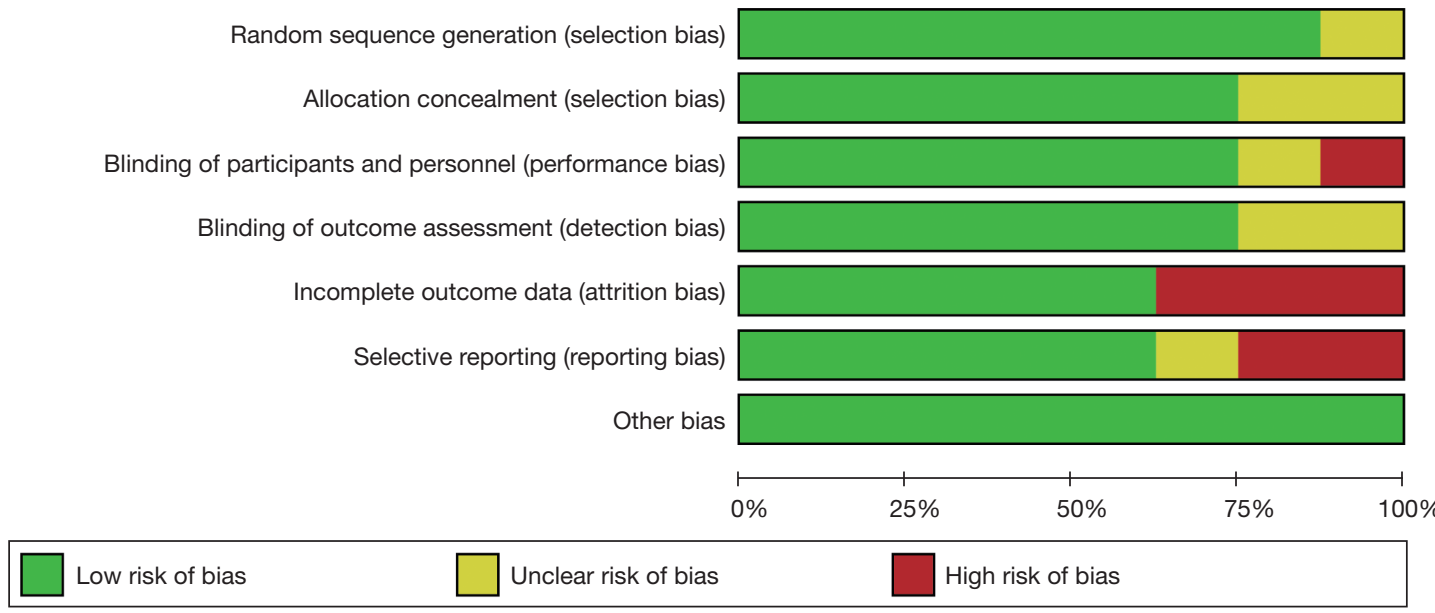

Figure 2 Proportion of studies with low (green), high (red), or unclear (yellow) risk of bias.

$-0.32 \mathrm{~g} / \mathrm{dL} ; 95 \%$ confidence interval (CI): $(-0.55,-0.08)$; $\mathrm{P}=0.008$; Figure 4], with significant heterogeneity $\left(\mathrm{I}^{2}=92 \%\right.$; $\mathrm{P}<0.00001)$. The $\mathrm{I}^{2}$ of the sensitivity analysis for serum albumin decreased to $80 \%$ by removing the study by Narain
2018 (21), indicating that the heterogeneity was mainly due to Narain 2018. The result was not significantly altered after sensitivity analysis [MD: $-0.25 \mathrm{~g} / \mathrm{dL} ; 95 \% \mathrm{CI}:(-0.44$, $-0.05) ; \mathrm{P}=0.01]$. 


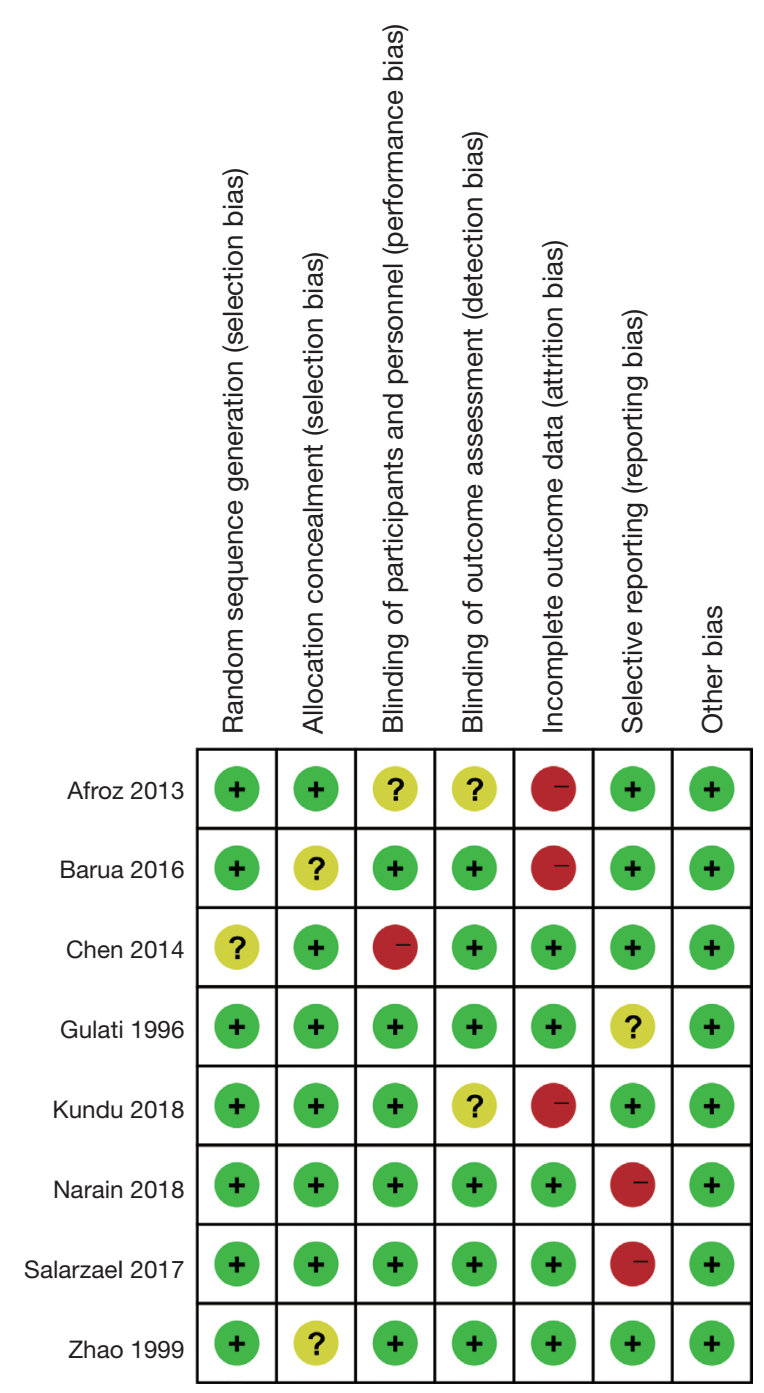

Figure 3 Risk of bias summary of the included studies.

In 2,654 patients across 3 studies, a lower level of serum total protein had a higher risk of PNS with UTI [MD: -0.16 g/dL; 95\% CI: (-0.20, -0.12); $\mathrm{P}<0.00001$; Figure 4], and the pooled studies were homogeneous $(\mathrm{P}=0.25$; $\left.I^{2}=29 \%\right)$.

\section{Urinary protein and serum urea nitrogen}

Five studies involving 3,019 patients reported on urinary protein, and the pooled analysis showed that a higher level of urinary protein significantly increased the risk of PNS with UTI [MD: $5.09 \mathrm{mg} / \mathrm{d}$; 95\% CI: (3.13, 7.05); $\mathrm{P}<0.00001 ;$ Figure 5], with significant heterogeneity $\left(\mathrm{I}^{2}=97 \% ; \mathrm{P}<0.00001\right)$. The $\mathrm{I}^{2}$ of the sensitivity analysis for urinary protein did not change significantly, suggesting that the meta-analysis result was robust.

Three studies reported on serum urea nitrogen, and the meta-analysis showed that a lower level of serum urea nitrogen had a higher risk of PNS with UTI [MD: $-0.10 \mathrm{mg} / \mathrm{dL}$; 95\% CI: $(-0.18,-0.02) ; \mathrm{P}=0.01$; Figure 5], and the pooled studies were homogeneous $\left(\mathrm{P}=0.57 ; \mathrm{I}^{2}=0 \%\right)$.

\section{Serum cholesterol and serum triglycerides}

Six studies reported on serum cholesterol, and the metaanalysis showed that the higher the level of serum cholesterol, the higher the risk of PNS with UTI [MD: $2.26 \mathrm{mg} / \mathrm{dL} ; 95 \%$ CI: (0.74, 3.78); $\mathrm{P}=0.004$; Figure 6]. The pooled studies were heterogeneous $\left(\mathrm{P}=0.0004 ; \mathrm{I}^{2}=78 \%\right)$. The $\mathrm{I}^{2}$ of the sensitivity analysis for serum cholesterol decreased to $52 \%$ by removing the study by Salarzaei 2017 (20), indicating that the heterogeneity was mainly due to Salarzaei 2017. However, the result was not significantly changed after sensitivity analysis [MD: $2.72 \mathrm{~g} / \mathrm{dL} ; 95 \% \mathrm{CI}$ : $(-1.79,3.65) ; \mathrm{P}<0.00001]$.

In 288 patients across 3 studies, the pooled analysis showed that the level of serum triglycerides had no association with the risk of PNS with UTI [MD: $-56.92 \mathrm{mg} / \mathrm{dL}$; $95 \%$ CI: (-143.44, 29.61); P=0.20; Figure 6]. The pooled studies were heterogeneous $\left(\mathrm{P}=0.02 ; \mathrm{I}^{2}=74 \%\right)$, and the result was robust after sensitivity analysis.

\section{Serum creatinine}

Four studies involving 2,776 patients reported on serum creatinine, and the pooled analysis showed that the level of serum creatinine had no association with the risk of PNS with UTI [MD: $0.02 \mathrm{mg} / \mathrm{dL}$; 95\% CI: $(-0.17,0.20)$; $\mathrm{P}=0.87$; Figure 7], with significant heterogeneity $\left(\mathrm{I}^{2}=92 \%\right.$; $\mathrm{P}<0.00001)$. The $\mathrm{I}^{2}$ of the sensitivity analysis for serum albumin decreased to $50 \%$ by removing the study by Chen 2014 (24), indicating that the heterogeneity was mainly due to Chen 2014. The result was not significantly changed after sensitivity analysis [MD: $-0.08 \mathrm{mg} / \mathrm{dL}$; $95 \% \mathrm{CI}$ : $(-0.16$, 0.01); $\mathrm{P}=0.09]$.

\section{Publication bias}

A funnel plot was generated to qualitatively evaluate the publication bias for serum albumin. The shape of the funnel plot showed some evidence of asymmetry (Figure 8), however, Egger's test was nonsignificant $(\mathrm{P}=0.58)$, which indicated that there was no obvious publication bias. 


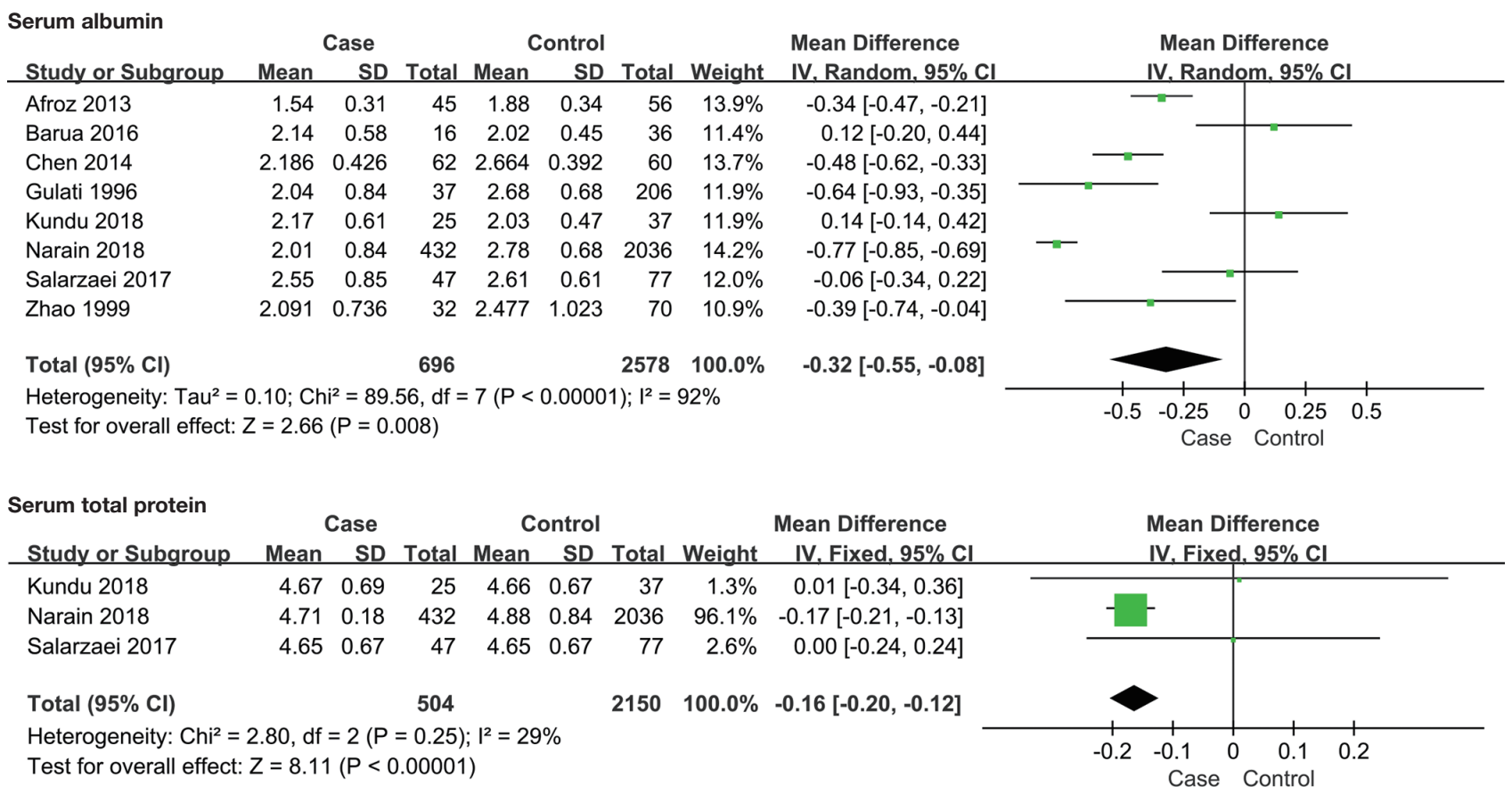

Figure 4 Forest plot: PNS with UTI versus PNS without UTI for serum albumin and serum total protein. PNS, primary nephrotic syndrome; UTI, urinary tract infection.

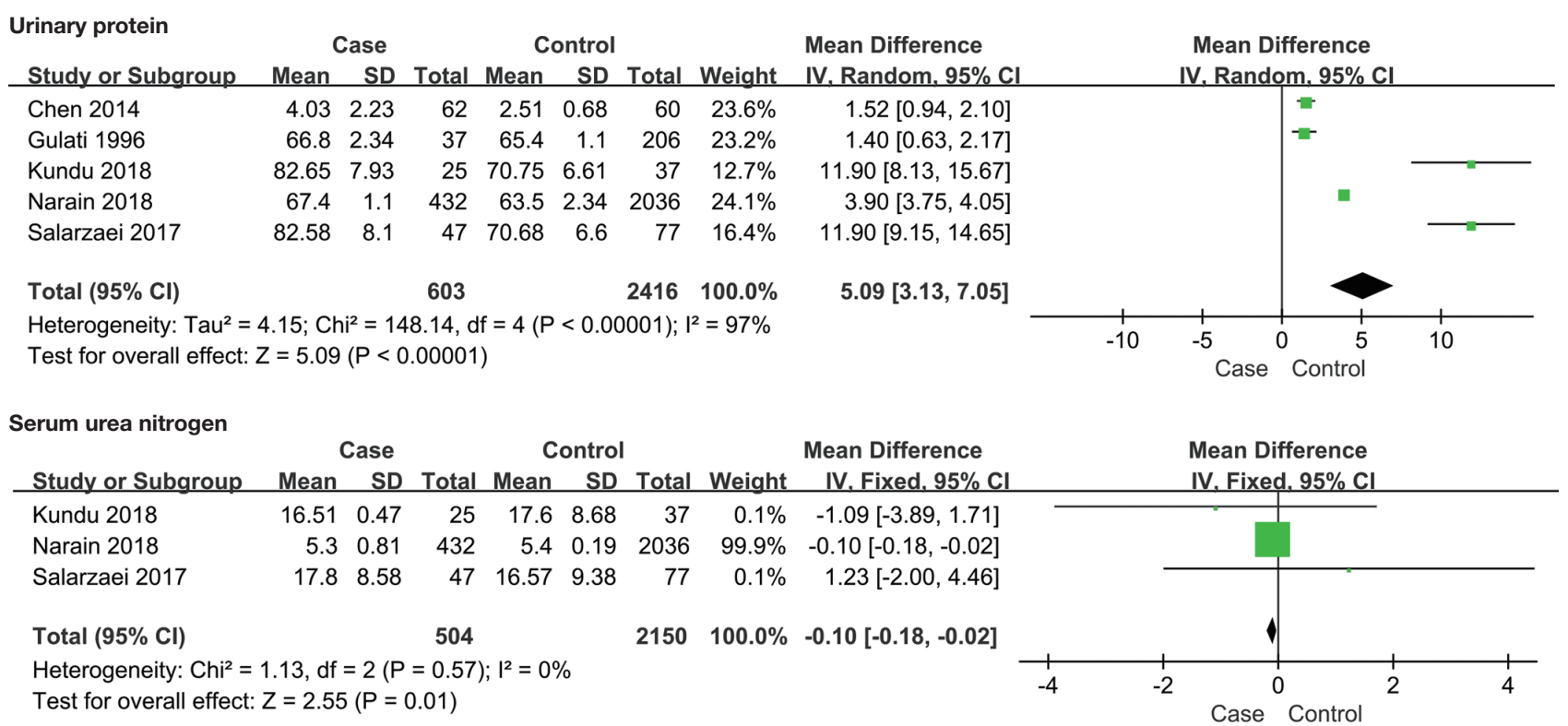

Figure 5 Forest plot: PNS with UTI versus PNS without UTI for urinary protein and serum urea nitrogen. PNS, primary nephrotic syndrome; UTI, urinary tract infection. 


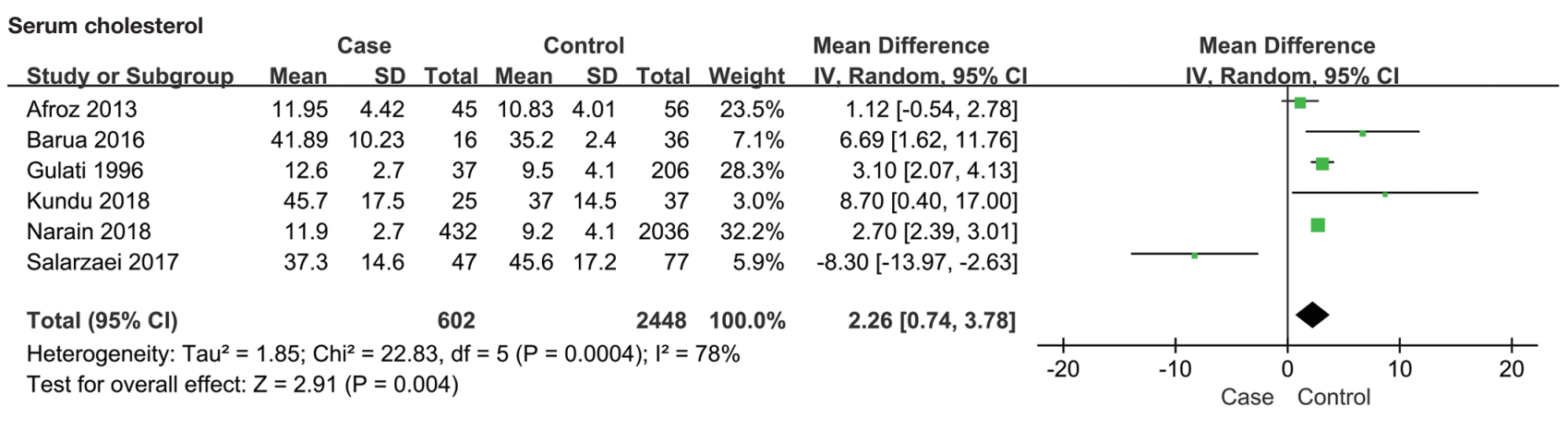

\begin{tabular}{|c|c|c|c|c|c|c|c|c|c|}
\hline \multirow[b]{2}{*}{ Study or Subgroup } & \multicolumn{2}{|c|}{ Case } & \multirow{2}{*}{\multicolumn{3}{|c|}{\begin{tabular}{cc} 
& \multicolumn{2}{c}{ Control } \\
Total Mean & SD
\end{tabular}}} & \multirow[b]{2}{*}{ Total } & \multirow[b]{2}{*}{ Weight } & \multirow{2}{*}{$\begin{array}{l}\text { Mean Difference } \\
\quad \text { IV. Random, } 95 \% \mathrm{Cl}\end{array}$} & \multirow{2}{*}{$\begin{array}{c}\text { Mean Difference } \\
\text { IV. Random. } 95 \% \mathrm{Cl}\end{array}$} \\
\hline & Mean & SD & & & & & & & \\
\hline Kundu 2018 & 337 & 194 & 25 & 439 & 205 & 37 & $28.1 \%$ & $-102.00[-202.73,-1.27]$ & \\
\hline Salarzaei 2017 & 335 & 195 & 47 & 436 & 201 & 77 & $34.6 \%$ & $-101.00[-172.58,-29.42]$ & \\
\hline Zhao 1999 & 251 & 151 & 32 & 233 & 124 & 70 & $37.3 \%$ & $18.00[-41.84,77.84]$ & 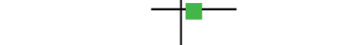 \\
\hline Total $(95 \% \mathrm{Cl})$ & & & 104 & & & 184 & $100.0 \%$ & $-56.92[-143.44,29.61]$ & \\
\hline \multicolumn{9}{|c|}{$\begin{array}{l}\text { Heterogeneity: } \mathrm{Tau}^{2}=4295.05 ; \mathrm{Chi}^{2}=7.83, \mathrm{df}=2(\mathrm{P}=0.02) ; \mathrm{I}^{2}=74 \% \\
\text { Test for overall effect: } Z=1.29(P=0.20)\end{array}$} & 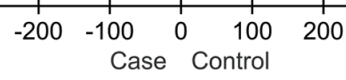 \\
\hline
\end{tabular}

Figure 6 Forest plot: PNS with UTI versus PNS without UTI for serum cholesterol and serum triglycerides. PNS, primary nephrotic syndrome; UTI, urinary tract infection.

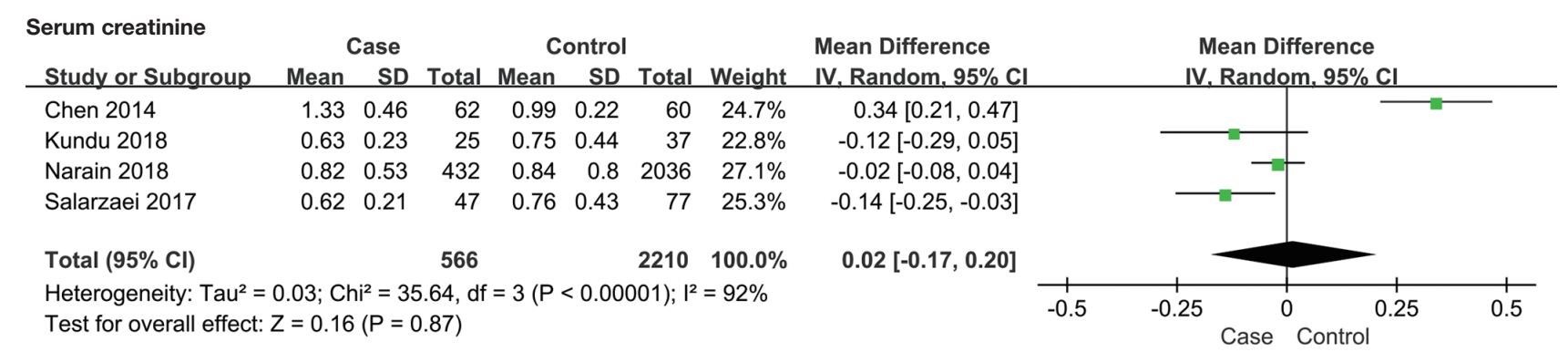

Figure 7 Forest plot: PNS with UTI versus PNS without UTI for serum creatinine. PNS, primary nephrotic syndrome; UTI, urinary tract infection.

\section{Discussion}

Clinical studies suggest that the reasons for PNS combined with UTI are as follows: (I) renal function is damaged and urinary protein level is increased; (II) residual proteinuria in the urethra is a good medium for pathogen growth; (III) hypoproteinemia leads to a decrease in leukocyte production; (IV) the most effective drugs for PNS are glucocorticoids and immunosuppressants $(27,28)$. At present, the incidence of PNS combined with UTI is increasing year by year, and has become the primary problem in the prevention and control of infectious diseases all over the world $(29,30)$.

Due to tissue edema, loss of immunoglobulins, and the use of immunosuppressants, the defense system of children with PNS is damaged, leading to low immunity and infection, which may even be life-threatening (31). In this paper, the risk factors of PNS with UTI were studied by meta-analysis.

This study showed that the levels of serum albumin, serum total protein, urinary protein, serum urea nitrogen, and serum cholesterol can affect the development of PNS with UTI. Specifically, a low level of serum albumin [MD: $-0.32 \mathrm{~g} / \mathrm{dL}$; $95 \%$ CI: $(-0.55,-0.08) ; \mathrm{P}=0.008]$, a low level of serum total protein [MD: $-0.16 \mathrm{~g} / \mathrm{dL} ; 95 \%$ CI: $(-0.20$, $-0.12) ; \mathrm{P}<0.00001]$, a high level of urinary protein $[\mathrm{MD}$ : $5.09 \mathrm{mg} / \mathrm{d}$; 95\% CI: $(3.13,7.05) ; \mathrm{P}<0.00001$ ], a lower level 


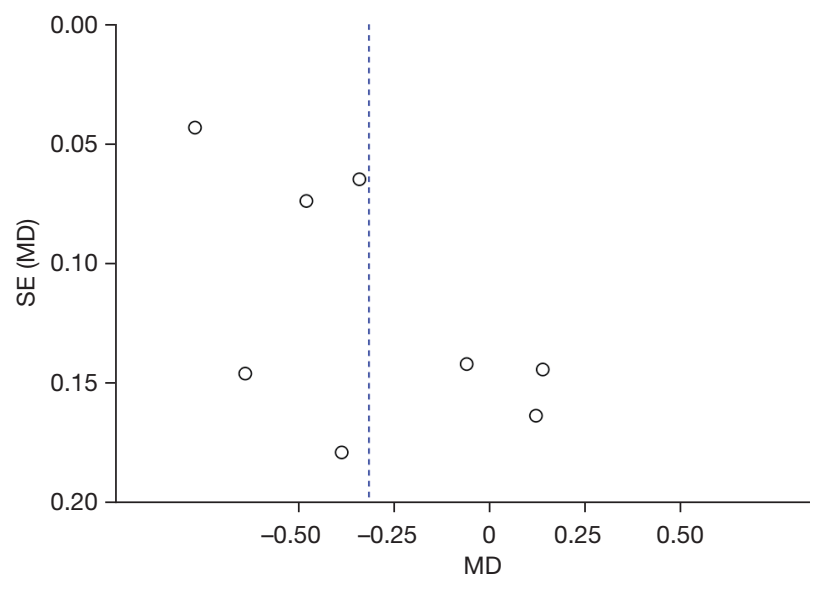

Figure 8 Funnel plot for potential publication bias.

of serum urea nitrogen [MD: $-0.10 \mathrm{mg} / \mathrm{dL}$; $95 \%$ CI: $(-0.18$, -0.02); $\mathrm{P}=0.01$ ], and a higher level of serum cholesterol [MD: $2.26 \mathrm{mg} / \mathrm{dL}$; 95\% CI: $(0.74,3.78) ; \mathrm{P}=0.004]$ were the risk factors for PNS with UTI in children.

The loss of plasma protein from urine and the protein filtered out from the glomerulus are metabolized in renal tubules, leading to hypoproteinemia, low resistance, malnutrition, and urethral mucosal edema in children, making them more prone to UTI (32). Some studies have pointed out that hypercholesterolemia can inhibit the synthesis of cell membrane proteins, block the expression of cell membrane molecules and adhesion molecules, and can affect the mutual recognition and contact between cells. It can further affect the recognition, proliferation, activation, and differentiation of immune cells, damage humoral and cellular immune functions, and weaken the antigen presentation, phagocytosis, and bactericidal effect of macrophages, ultimately leading to the occurrence of UTI $(33,34)$. Urinary residual proteinuria is a good culture medium for pathogens, so the higher the level of proteinuria, the higher the risk of UTI $(35,36)$.

There were some limitations in this meta-analysis. Firstly, some studies did not explain the diagnostic criteria of UTI and PNS, the description of the determination method of research factors was not detailed, some data was incomplete, the inclusion criteria were limited, and the final sample size was limited. Secondly, the heterogeneity tests showed that several outcome variables were highly heterogeneous, which may be related to the differences in measurement methods across different countries. In addition, the research factors were not comprehensive, such as only the analysis of serum albumin, urinary protein and other factors that be of interest to most researchers.

In conclusion, a low level of serum albumin, a low level of serum total protein, a high level of urinary protein, a low level of serum urea nitrogen, and a high level of serum cholesterol were the risk factors of PNS with UTI in children.

\section{Acknowledgments}

Funding: This work was supported by the research grants from the Key Research and Development in Hebei (No. 192777122D), and the Science and Technology Plan Project of Research and Development in Chengde (No. 201904A024).

\section{Footnote}

Reporting Checklist: The authors have completed the PRISMA reporting checklist. Available at https://dx.doi. org/10.21037/tp-21-468

Conflicts of Interest: All authors have completed the ICMJE uniform disclosure form (available at https://dx.doi. org/10.21037/tp-21-468). The authors have no conflicts of interest to declare.

Ethical Statement: The authors are accountable for all aspects of the work in ensuring that questions related to the accuracy or integrity of any part of the work are appropriately investigated and resolved.

Open Access Statement: This is an Open Access article distributed in accordance with the Creative Commons Attribution-NonCommercial-NoDerivs 4.0 International License (CC BY-NC-ND 4.0), which permits the noncommercial replication and distribution of the article with the strict proviso that no changes or edits are made and the original work is properly cited (including links to both the formal publication through the relevant DOI and the license). See: https://creativecommons.org/licenses/by-nc-nd/4.0/.

\section{References}

1. Kaddah A, Sabry S, Emil E, et al. Epidemiology of primary nephrotic syndrome in Egyptian children. J Nephrol 2012;25:732-7.

2. Candiano G, Musante L, Petretto A, et al. Proteomics of plasma and urine in primary nephrotic syndrome in 
children. Contrib Nephrol 2008;160:17-28.

3. Ajayan P, Krishnamurthy S, Biswal N, et al. Clinical spectrum and predictive risk factors of major infections in hospitalized children with nephrotic syndrome. Indian Pediatr 2013;50:779-81.

4. Wang T, Guo DY, Wei M, et al. Effect of low molecular heparin and simvastatin on hypercoagulabale state of primary nephrotic syndrome. Progress in Modern Biomedicine 2010;10:1529-32.

5. Rankin AJ, McQuarrie EP, Fox JG, et al. Venous thromboembolism in primary nephrotic syndrome - is the risk high enough to justify prophylactic anticoagulation? Nephron 2017;135:39-45.

6. Wei CC, Yu IW, Lin HW, et al. Occurrence of infection among children with nephrotic syndrome during hospitalizations. Nephrology (Carlton) 2012;17:681-8.

7. Larcombe J. Urinary tract infection in children. BMJ Clin Evid 2010;2010:0306.

8. Sultana S, Selimuzzaman M, Begum A, et al. Urinary tract infection in nephrotic syndrome. Bangladesh Renal J 2004;23:52-5.

9. Peng LN. Clinical pharmacists' pharmacy practice for a patient with nephrotic syndrome associated with urinary tract infection. evaluation and analysis of drug-use in hospitals of China 2014;(6):554-7, 558.

10. Sreenivasa B, Murthy CLS, Raghavendra K, et al. Urinary tract infection at presentation of nephrotic syndrome: a clinical evaluation. Indian J Child Health 2015;2:1-4.

11. Sorkhi H, Riahi SM, Ebrahimpour S, et al. Urinary tract infection in children with nephrotic syndrome: a systematic review and meta-analysis. Microb Pathog 2019;137:103718.

12. Teslariu O, Nechifor M. Divalent cations levels change in nephrotic syndrome. Rev Med Chir Soc Med Nat Iasi 2012;116:883-7.

13. Naseri M. Pneumococcal sepsis, peritonitis, and cellulitis at the first episode of nephrotic syndrome. Iran J Kidney Dis 2013;7:404-6.

14. Devdas JM, Bukelo MJ. Occurrence of urinary tract infection in children with nephrotic syndrome in a tertiary care hospital. J Evol Med Dent Sci 2015;4:17014-7.

15. Dunér F, Patrakka J, Xiao Z, et al. Dendrin expression in glomerulogenesis and in human minimal change nephrotic syndrome. Nephrol Dial Transplant 2008;23:2504-11.

16. Adeleke SI, Asani MO. Urinary tract infection in children with nephrotic syndrome in Kano, Nigeria. Ann Afr Med 2009;8:38-41.

17. Salomon R, Gagnadoux MF, Niaudet P. Intravenous cyclosporine therapy in recurrent nephrotic syndrome after renal transplantation in children. Transplantation 2003;75:810-4.

18. Cheong HI, Han HW, Park HW, et al. Early recurrent nephrotic syndrome after renal transplantation in children with focal segmental glomerulosclerosis. Nephrol Dial Transplant 2000;15:78-81.

19. Zhao GC, Wang XW, Liu XH. Analysis of humoral immunoglobulin in children with nephrotic syndrome complicated with urinary tract infection. Shanghai Journal of Immunol 1999;(5):311.

20. Salarzaei M, Saravani S, Heydari M, et al. Prevalence of urinary tract infection in children with nephrotic syndrome. Int J Pharm Sci Res 2017;8:1346-50.

21. Narain U, Gupta A. Urinary tract infection in children with nephrotic syndrome. Pediatr Infect Dis J 2018;37:144-6.

22. Kundu LC, Saha AK, Hassan MK, et al. Urinary tract infection in nephrotic syndrome-a study of 62 cases at Faridpur Medical College Hospital. Faridpur Medical College Journal 2018;13:35-9.

23. Gulati S, Kher V, Arora P, et al. Urinary tract infection in nephrotic syndrome. Pediatr Infect Dis J 1996;15:237-40.

24. Chen WB, Xu WF, Su YZ. Primary nephrotic syndrome complicated by urinary tract infection in children. Acta Academiae Medicinae Jiangxi 2014;(3):29-31, 36.

25. Barua T, Sultana R, Babul FK, et al. Urinary tract infection in nephrotic syndrome: a hospital based cross-sectional study. Chattagram Maa-O-Shishu Hospital Medical College Journal 2016;15:41-4.

26. Afroz S, Roy DK, Khan AH. Low serum immunglobulin $\mathrm{G}$ (IgG) during nephrosis is a predictor of urinary tract infection (UTI) in children with nephrotic syndrome. Mymensingh Med J 2013;22:336-41.

27. Zhang G, Li Q, Wang L, et al. The effects of inflammation on lipid accumulation in the kidneys of children with primary nephrotic syndrome. Inflammation 2011;34:645-52.

28. The primary nephrotic syndrome in children. Identification of patients with minimal change nephrotic syndrome from initial response to prednisone. A report of the International Study of Kidney Disease in Children. J Pediatr 1981;98:561-4.

29. Mirrakhimov AE, Ali AM, Barbaryan A, et al. Primary nephrotic syndrome in adults as a risk factor for pulmonary embolism: an up-to-date review of the literature. Int J Nephrol 2014;2014:916760.

30. Bakr A, Abul Hassan S, Shoker M, et al. Oxidant stress 
in primary nephrotic syndrome: does it modulate the response to corticosteroids? Pediatr Nephrol 2009;24:2375-80.

31. Choi HS, Kim CS, Ma SK, et al. Treatment of hyperlipidemia with proprotein convertase subtilisin/kexin type 9 inhibitor in a patient with nephrotic syndrome: a case report. Ann Palliat Med 2020;9:2357-60.

32. Ru L, Luo Q, Guo YF. Analysis of pathogen and antimicrobial resistance in children with urinary tract infection and nephrotic syndrome accompanied by urinary tract infection. Journal of Clinical Pediatrics 2014;32:43-7.

33. Prandota J. Urinary tract diseases revealed after DTP vaccination in infants and young children: cytokine irregularities and down-regulation of cytochrome P-450 enzymes induced by the vaccine may uncover latent diseases in genetically predisposed subjects. Am J Ther

Cite this article as: Zheng Z, Chen G, Jing X, Liu L, Yang L. The risk factors for children with primary nephrotic syndrome: a systematic review and meta-analysis. Transl Pediatr 2021;10(12):3184-3193. doi: 10.21037/tp-21-468
2004;11:344-53.

34. Al-Mendalawi MD. Urinary tract infection in Iraqi children. Saudi J Kidney Dis Transpl 2010;21:961-3.

35. Canaud G, Dion D, Zuber J, et al. Recurrence of nephrotic syndrome after transplantation in a mixed population of children and adults: course of glomerular lesions and value of the Columbia classification of histological variants of focal and segmental glomerulosclerosis (FSGS). Nephrol Dial Transplant 2010;25:1321-8.

36. Adedoyin OT, Ojuawo IA, Odimayo MS, et al. Urinary tract infections in children with primary nephrotic syndrome and acute glomerulonephritis. West Afr J Med 2010;29:235-8.

(English Language Editor: C. Betlazar-Maseh) 